УДК 602.4:634.773

\title{
РАЗРАБОТКА ТЕХНОЛОГИИ ПОЛУЧЕНИЯ ПРОРОЩЕННЫХ СЕМЯН ОБЛЕПИХИ
}

\author{
(C) А.М. Золотарева, М.Г. Заятуева, Нямдорж Болорцэцэг, С.Б. Ринчинова *
}

\author{
Восточно-Сибирский государственный университет технологий \\ и управления, ул. Ключевская, 40б, Улан-Удэ, 670013 (Россия), \\ e-mail: zolotareva_am@mail.ru
}

Разработана технология получения пророщенных семян облепихи. Изменения в химическом составе семян облепихи при проращивании изучались физико-химическими методами. Установлены модификационные изменения микроструктуры семян облепихи с использованием электронного микроскопирования с системой микроанализа INCA. Разработаны частные технологии использования пророщенных семян облепихи в производстве функциональных мучных кондитерских изделий.

Ключевые слова: семена облепихи, биологически активные вещества, проращивание, витамины, растительное сырье.

\section{Введение}

В настоящее время, в условиях адаптации к рыночной экономике, на первое место выходят проблемы рационального использования сырьевых ресурсов. Поэтому проведение научных исследований, направленных на развитие отечественного агропромышленного комплекса, является важнейшим фактором реализации концепции государственной политики в области рационального природопользования [1].

В районах Сибири, на Дальнем Востоке, в Монголии облепиха является промышленной ягодной культурой. Один из побочных продуктов переработки ягод облепихи при производстве масла, сока, пасты, напитков - облепиховые семена. На практике природный ресурс облепиховых семян используется нерационально. Хотя в последнее время семена облепихи привлекают ученых как источник «белого» масла, которое в Китае используют в качестве лечебного и профилактического средства.

В настоящее время в литературе приводятся сведения об использовании пророщенных семян при производстве продуктов питания функционального назначения. Прорастание - это переход семени из состояния покоя к росту зародыша. Во время прорастания находящиеся в семенах ферменты расщепляют сложные белки, жиры и углеводы на более простые вещества, которые необходимы для роста будущего растения. И поэтому при использовании в пищу прорастающих зерен организм человека получает и усваивает уже обработанные ферментами вещества. Прорастающие семена обладают огромным энергетическим потенциалом, содержат все необходимые жизненные компоненты и снабжены системой, которая способствует их усвоению.

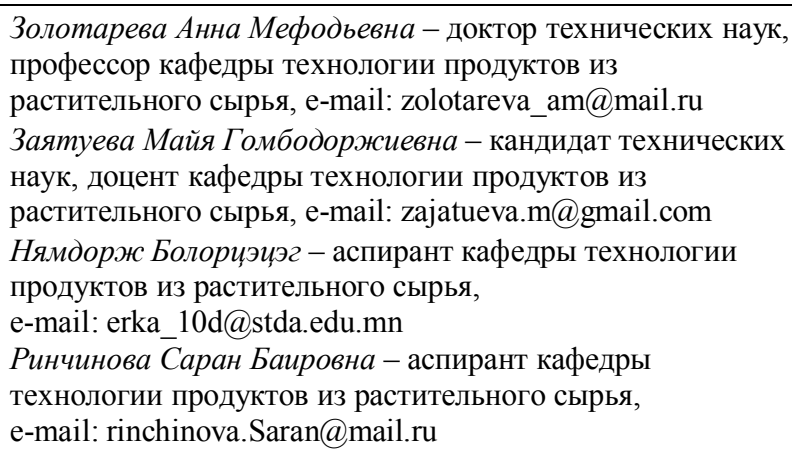

Именно это уникальное сочетание и определяет их мощное оздоравливающее действие на организм человека [2].

В связи с этим изучение свойств пророщенных семян облепихи с последующим использованием их в рецептурах продуктов питания является актуальным.

Цель настоящего исследования - разработка технологии получения пророщенных семян облепихи.

\footnotetext{
* Автор, с которым следует вести переписку.
} 


\section{Материальи и методы}

Проращивание определяли по способности семян образовывать нормально развитые проростки [3]. Экстрактивность несоложеных зернопродуктов определяли методом опытного затирания зернопродуктов с солодовой вытяжкой [4]. Микрофотографии получили на электронном микроскопе JSM - 6510LVJEOL с системой микроанализа INCA. Количество белков определяли по содержанию общего азота методом Кельдаля [5]. Количественное содержание массовой доли жира устанавливали по ГОСТ 8756.21-89 [6]. Углеводный состав изучали по массовой доле редуцирующих углеводов, общему сахару и сахару, согласно ГОСТ 8756.13-87, перманганатным методом, основанным на способности карбонильных групп сахаров восстанавливать в щелочной среде оксида меди (II) до оксида меди (I); содержание пектиновых веществ объемным методом по С.Я. Райк, основанным на осаждении пектиновой кислоты сульфатом меди и последующем объемном йодметрическом определении связанной меди. Целлюлозу - по модифицированному методу Кюршнера и Хоффера, основанному на окислительном разрушении и растворении растворами азотной кислоты в спирте и спиртовой щелочи веществ, сопутствующих клетчатке. Целлюлолитическую активность целлюлаз определяли колориметрическим методом с применением реактива Шомодьи Нельсона по количеству образовавшихся редуцирующих углеводов [5]. Количественное содержание биологически активных веществ устанавливали в первую очередь по содержанию витаминов. Аскорбиновую кислоту методом, основанным на извлечении витамина С водным раствором уксусной кислоты и фосфорного ангидрида, дальнейшим окислением аскорбиновой кислоты (АК) в дегидроаскорбиновую (ДАК) и последующим проведением реакции с $о$-фенилендиамином. Метод определения токоферолов заключается в щелочном гидролизе пробы, экстракции гексаном неомыляемой части, с последующим разделением полученного экстракта на фракции методом ВЭЖХ [7]. Тиамин и рибофлавин определяли с помощью системы капиллярного электрофореза Капель-105M*, предназначеного для качественных и количественных исследований различных объектов. Количественное определение суммы флавоноидов проводили спектрофотометрически в пересчете на рутин [8].

\section{Результаты и обсуждение}

Нами в эксперименте изучена возможность получения пророщенных семян облепихи (ПСО). На рисунке 1 представлен график всхожести семян облепихи.

Из данных рисунка 1 следует, что для семян плодовых культур энергия прорастания в 2 раза меньше, чем для зерновых культур. Всхожесть для семян облепихи составляет 8 дней. Это обусловлено морфологическим составом семян, в частности высокой прочностью оболочки, в основном состоящий из целлюлозы, содержание которой в облепиховом семени составляет порядка $18 \%$.

При проращивании в семени начинает проклевываться корешок, длина которого постепенно увеличивается. Одновременно растет и зародышевый листок, невидимый в первые дни проращивания, так как находится под оболочкой. На рисунке 2а и 26 представлены фото семян облепихи.

Органолептическая оценка исследуемых образцов дана в таблице 1.

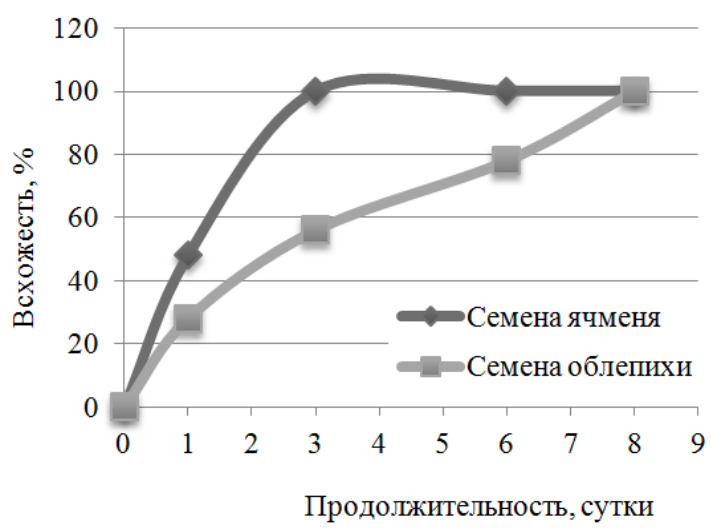

Рис. 1. Всхожесть семян растений 

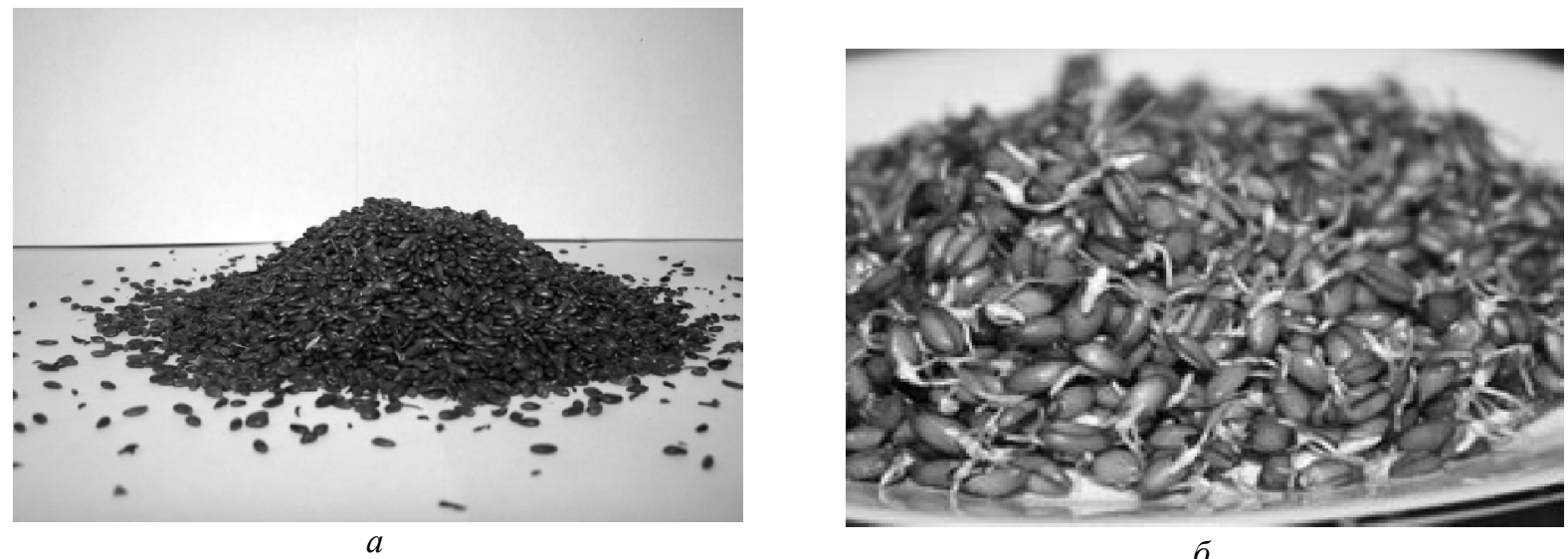

$\sigma$

Рис. 2. Исходные (а) и пророщенные (б) семена облепихи

Таблица 1. Органолептические показатели пророщенных семян облепихи

\begin{tabular}{c|l|l}
\hline Показатели & \multicolumn{1}{|c}{ Семена облепихи } & \multicolumn{1}{|c}{ Пророщенные семена облепихи } \\
\hline Внешний вид & Однородная семенная масса, не содержащая & Однородная семенная масса, не содержащая \\
& плесневых семян и различных вредителей. & плесневых семян и различных вредителей. \\
& От светло-коричневого до коричневого. & От светло-коричневого до коричневого. \\
& Отсутствуют зеленоватые и темные тона, & Отсутствуют зеленоватые и темные тона, \\
обусловленные плесенью. & обусловленные плесенью. \\
Запах & $\begin{array}{l}\text { Ярко выраженный. Насыщенный запах, } \\
\text { Володовый запах. }\end{array}$ \\
& свойственный данному продукту. & Специфический масличный привкус. \\
\hline
\end{tabular}

Сенсорные показатели свидетельствуют, что пророщенные семена облепихи отличаются от ячменного солода специфическим масличным привкусом и более насыщенным коричневым оттенком.

Сушат семена до влажности 14\%, при которой ферментативные процессы прекращаются. Накопившиеся в семенах продукты ферментного распада белков и углеводов под влиянием высокой температуры сушки взаимодействуют между собой с образованием меланоидов, которые обладают характерным цветом, вкусом и запахом, что придает облепиховому солоду приятный фруктовый аромат.

Технология проращивания семян облепихи представлена на рисунке 3 .

Под воздействием собственных ферментов микроструктура анатомических частей семян претерпевает необратимые изменения. Влияния процесса проращивания на микроструктуру семян демонстрируют рисунки 4-6.

На рисунках представлены микрофотографии центральной части эндосперма пророщенных семян облепихи, полученные на электронном микроскопе JSM-6510LVJEOL с системой микроанализа INCA.*

Сравнение результатов исследования образцов семян облепихи показало, что при продольном разрезе контрольный образец (рис. 4a) характеризуется наличием агрегированных продольных включений в виде упорядоченных гранул. На рисунке 46 микроструктура облепихового солода приобретает форму в виде сферических глобул.

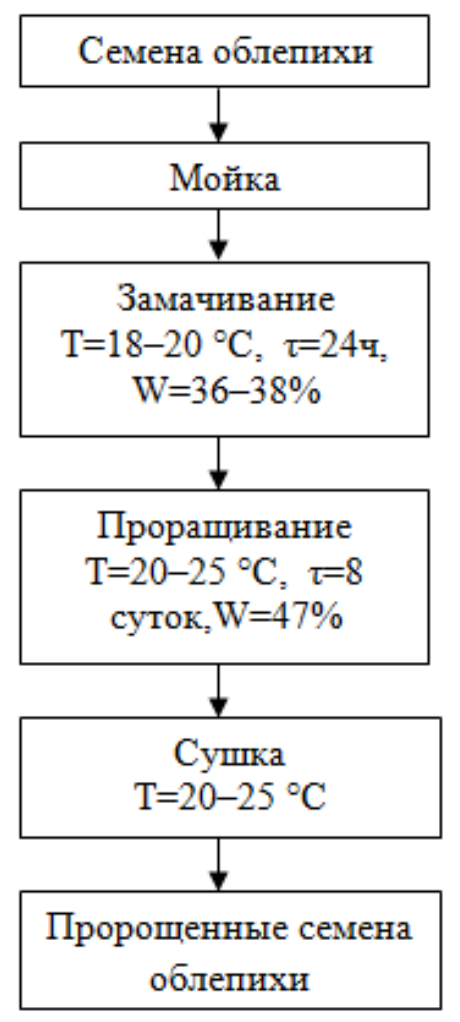

Рис. 3. Технологическая схема проращивания семян облепихи

\footnotetext{
* Микроструктура семян облепихи была определена в центре коллективного использования научного оборудования «Прогресс» Восточно-Сибирского государственного университета технологий и управления.
} 
При поперечном разрезе видно, что микроструктура семян облепихи (рис. 5а) имеет форму конденсированных пиронозных колец. При проращивании (рис. 5б) микроструктура пиронозных колец увеличивается на 15-19\%, приобретая выпуклую сферическую форму.

При проращивании семян облепихи в связи с денутурацией белка наблюдается изменение белковых матриц, что, в свою очередь, оказывает влияние на расположение крахмальных гранул, а также на белковые переслойки и жировые компоненты.

Исследования микроструктуры семян облепихи после проращивания показывает, что характерная сплошная непрерывная фаза целлюлозной оболочки семян облепихи вследствие ферментной деструкции уменьшилась в среднем на 28,9\%, что подтверждают полученные данные (см. рис. 1).

Химический состав пророщенных семян облепихи представлен в таблице 2.

Анализ химического состава показывает, что повышение активности ферментов в прорастающем семени обусловливает изменение его химического состава, при этом наибольшие изменения претерпевают биополимеры. Количество целлюлозы в пророщенных семенах облепихи снизилось на $12 \%$, что связано с тем, что наряду с растворением клеточных стенок эндосперма, примерно такое же количество клетчатки образуется в новых вегетативных органах, а часть углеводов расходуется на дыхание. Содержание белков снижается незначительно, обусловливая возрастание свободных аминокислот. Установлено, что проращивание повышает содержание витаминов, в том числе токоферолов, аскорбиновой кислоты, тиамина, в среднем на $40 \%$.

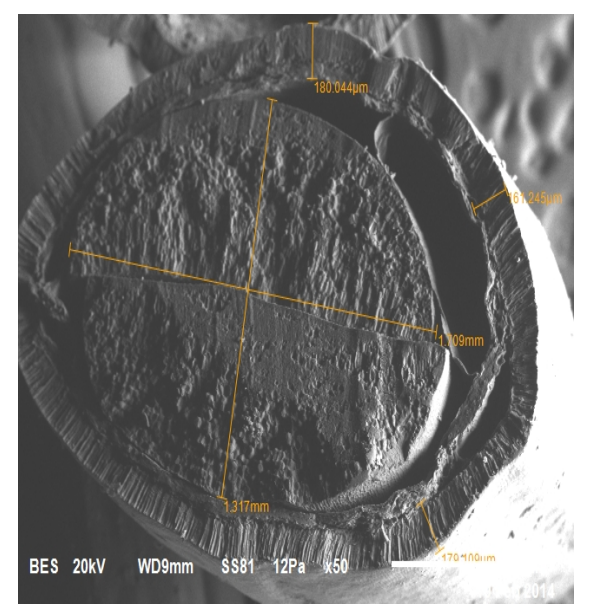

$a$

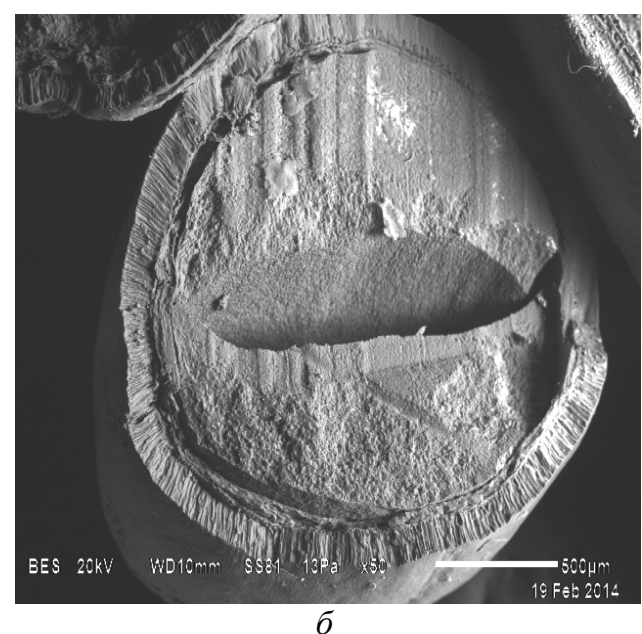

$\sigma$

Рис. 4. Микроструктура исходных (a) и пророщенных (б) семян облепихи ×50
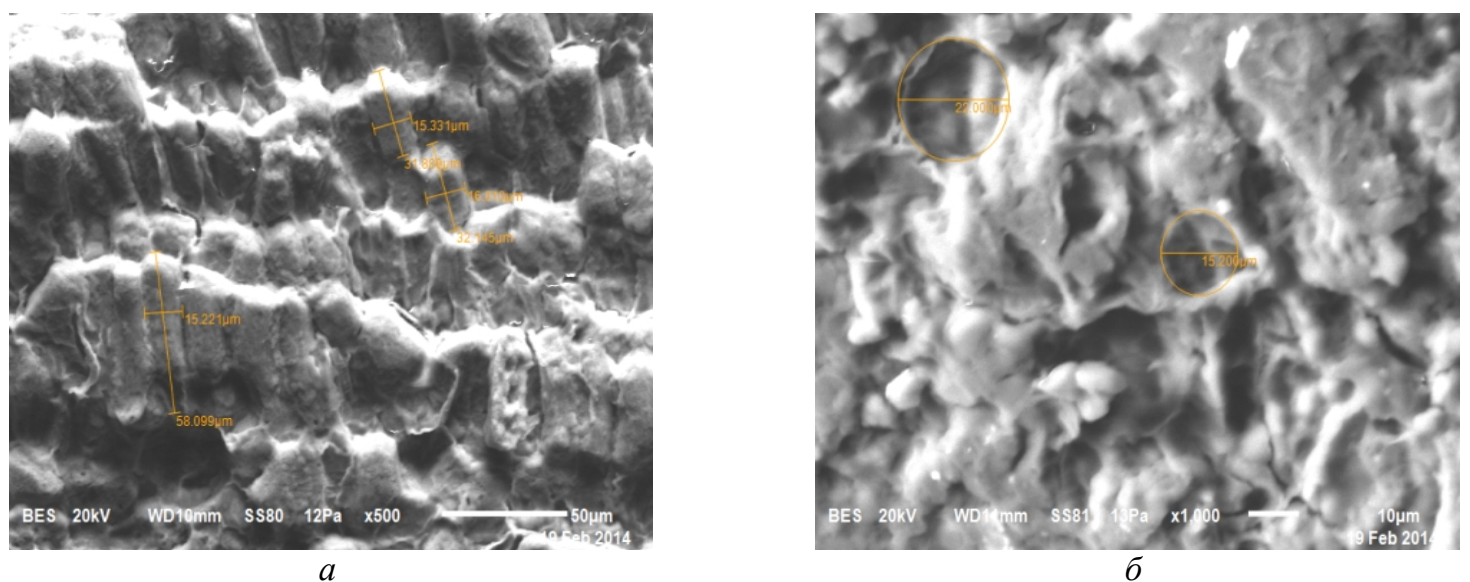

Рис. 5. Микроструктура семян облепихи (продольный разрез) (a) и пророщенных семян облепихи (поперечный разрез) (б) ×500 

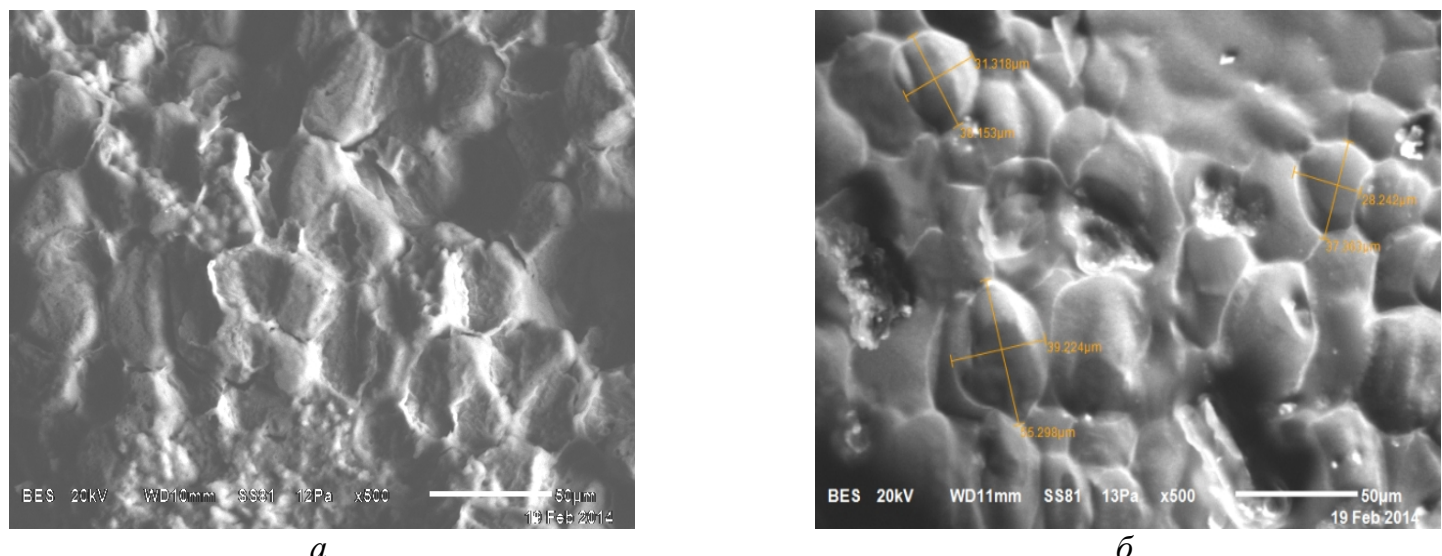

Рис. 6. Микроструктура семян облепихи (продольный разрез) (a) и пророщенных семян облепихи (поперечный разрез) (б) ×500

Таблица 2. Химический состав семян облепихи

\begin{tabular}{l|c|c}
\hline \multicolumn{1}{c|}{ Показатели } & Семена облепихи & Пророщенные семена облепихи \\
\hline Белки, \% & $25,06 \pm 1,14$ & $24,15 \pm 1,13$ \\
Липиды, \% & $15,45 \pm 0,75$ & $15,01 \pm 0,68$ \\
Углеводы, \% & $29,22 \pm 1,12$ & $20,14 \pm 1,06$ \\
Минеральные вещества & $4,53 \pm 0,15$ & $4,3 \pm 0,14$ \\
Каратиноиды, мг\% & $4,21 \pm 0,22$ & $4,11 \pm 0,16$ \\
Флавоноиды, \% & $1,54 \pm 0,06$ & $3,28 \pm 2,28$ \\
Токоферол, мг/100 & $62,15 \pm 2,13$ & $87,16 \pm 2,15$ \\
Аскорбиновая кислота, мг\% & $6,54 \pm 0,32$ & $8,85 \pm 0,39$ \\
Тиамин, мг\% & $1,02 \pm 0,07$ & $1,44 \pm 0,06$ \\
Рибофлавин, мг\% & $0,25 \pm 0,01$ & $0,27 \pm 0,03$ \\
\hline
\end{tabular}

Наряду с преобразованием химического состава, происходят цитологические изменения, т.е. нарушение клеточной структуры путем растворение эндосперма. Стенки клеток эндосперма, состоящие в основном из полисахаридов второго порядка и белков, подвергаются гидролизу под действием образующихся во время прорастания ферментов (цитологических, протеолитических, пектолитических), что приводит к разрушению стенок клеток, т.е. происходит их растворение или разрыхление. В результате эндосперм становится рассыпчато-мягким. Пророщенные семена облепихи содержат значительно меньше экстрактивных веществ, нежели семена ячменя, поскольку в химическом составе последних преобладает большое количество водорастворимых веществ, в том числе крахмала [9]. В эксперименте установлено, что экстрактивность семян облепихи значительно ниже, чем у ячменя, и составляет 25,68\%, однако по сравнению с неферментированными семенами облепихи экстрактивность ПСО возросла на $33,3 \%$.

Анализ химического состава показывает, что ПСО имеют высокую биологическую ценность, что позволяет использовать его в качестве компонента при создании продуктов функционального питания.

Чаще всего пророщенное зерно используют для приготовления хлеба и хлебобулочных изделий как компонент теста с целью повышения биологической ценности и улучшения функционально-технологических свойств готового продукта [10].

Известен пищевой функциональный продукт «Талкан», содержащий зерновую основу, в качестве которой используют пророщенное зерно и добавки (сушеные плоды и ягоды) при определенном соотношении компонентов [11].

Нами разработана технология производства кекса с включением ПСО. Техническим результатом изобретения [12] является создание кекса с функциональными свойствами за счет обогащения биологически активными веществами и оптимального соотношения компонентов, что обеспечивает повышение влагоудерживающей способности, увеличение выхода продукта и улучшение органолептических свойств в результате гармонизации рецептуры, а также снижение себестоимости готового продукта. 
При использовании в пищу прорастающих зерен организм человека получает и усваивает уже обработанные ферментами вещества. Исключительная ценность пророщенных семян заключается в том, что проростки обладают всеми природными биологическими свойствами целостного живого организма, тогда как большинство привычных для нас растительных продуктов (листья, клубни, стебли, плоды) являются лишь частями растения. Прорастающие семена обладают огромным энергетическим потенциалом, содержат все необходимые жизненные компоненты и снабжены системой, которая способствует их усвоению. Именно это их уникальное сочетание и определяет их мощное оздоравливающее действие на организм человека.

Новые подходы к переработке облепихового сырья на основе физико-химических и биохимических превращений не только обеспечивают целенаправленное превращение структурных элементов клетки и сохранение на исходном уровне биологически активных веществ, но и позволяют наиболее полно использовать все ресурсы, заложенные в этом растении.

\section{Bbыводbl}

1. На основании проведенных исследований и полученных данных разработана технология получения пророщенных семян облепихи.

2. Установлено, что процесс проращивания семян облепихи обусловливает повышение содержания БАВ, витаминов, в том числе токоферолов, аскорбиновой кислоты, тиамина, в среднем на $40 \%$.

3. Исследования микроструктуры семян облепихи после проращивания показали, что характерная сплошная непрерывная фаза целлюлозной оболочки семян облепихи вследствие ферментной деструкции уменьшилась в среднем на 28,9\%.

4. Анализ химического состава показывает, что ПСО имеют высокую биологическую ценность, что позволяет использовать их в качестве компонента при создании продуктов функционального питания.

5. Разработаны частные технологии использования пророщенных семян облепихи в производстве функциональных мучных кондитерских изделий.

\section{Список литературь}

1. Арбаков К.А., Захарова Г.М. Облепиха в Бурятии. Улан-Удэ, 2000. 140 с.

2. Золотарева А.М., Чиркина Т.Ф. Вторичные сырьевые ресурсы переработки растительного сырья : учеб. пособие. Улан-Удэ, 2011. 130 с.

3. Патент 2463809 (РФ). Пищевой функциональный продукт «Талкан» из пророщенного зерна и способ его производства / Ф.М. Кадыров, А.С. Акрамова, М.У. Бабаев, М.Р. Хакимова, С.И. Игамбердиева. 20.10.2012.

4. Косминский Г.И. Технология солода, пива и безалкогольных напитков. Минск, 1998. 158 с.

5. Методы биохимического исследования растений / под ред. А.И. Ермаковой. Л., 1987. 428 с.

6. Технохимический контроль жиров и жирозаменителей : учеб. пособие / под ред. проф. О.Б. Рудакова. СПб., $2011.576 \mathrm{c}$

7. Методика выполнения измерений массовой доли витаминов А и Е в пробах пищевых продуктов и продовольственного сырья на анализаторе жидкости «Флюорат-02». Методика 04-07-96. СПб., 1996. 39 с.

8. Государственная Фармакопея СССР. ХІ изд. Вып. 2. М., 1990. 642 с.

9. Скурихин И.М., Нечаев А.П. Все о пище с точки зрения химика. М., 1991. 288 с.

10. Патент 2524827 (РФ). Способ производства зернового хлеба / В.И. Акиншин. 27.05.1997.

11. Патент 2527295 (РФ). Способ производства пищевых продуктов быстрого приготовления на основе пророщенных злаков / Я.Д. Марцынив, Е.В. Москалев. 27.12.2014.

12. Патент 254747 (РФ). Кекс «Ростик» / А.М. Золотарева, С.Б. Ринчинова, Нямдорж Болорцэцэг. 10.04.2015.

Поступило в редакиию 22 апреля 2015 2. 
Zolotareva A.M., Zaiatueva M.G., Niamdorzh Bolortsetseg, Rinchinova S.B. ${ }^{*}$ EVELOPMENT OF TECHNOLOGY FOR BUCKTHORN SEED SPROUTS

East-Siberian State University of Technology and Management, Kliuchevskaia st., 40b, Ulan-Ude, 670013, (Russia), e-mail: zolotareva_am@mail.ru

The technology of germinated seeds of sea buckthorn. Changes in the chemical composition of the seeds in the germination-Lepikhov studied by physicochemical methods. Installed modification changes the microstructure of sea buckthorn seeds using electronic mikrosokopirovaniya a microanalysis system INCA. Developed private technology use germinated seeds of sea buckthorn in the production of functional flour confectionery products.

Keywords: sea buckthorn seeds, biologically active substances, germination, vitamins, vegetable sy-Riez.

\section{References}

1. Арбаков К.А., Захарова Г.М. Облепиха в Бурятии. [Seabuckthorn in Buryatia]. Ulan-Ude, 2000, 140 p. (in Russ.).

2. Zolotareva A.M., Chirkina T.F. Vtorichnye syr'evye resursy pererabotki rastitel'nogo syr'ia. [Secondary raw materials processing of vegetable raw materials]. Ulan-Ude, 2011, 130 p. (in Russ.).

3. Patent 2463809 (RU). 20.10.2012. (in Russ.).

4. Kosminskii G.I. Tekhnologiia soloda, piva i bezalkogol'nykh napitkov. [Technology malt, beer and soft drinks]. Minsk, 1998, 158 c. (in Russ.).

5. Metody biokhimicheskogo issledovaniia rastenii. [Methods of biochemical research plant]. Ed. A.I. Ermakova. Leningrad, 1987, 428 p. (in Russ.).

6. Tekhnokhimicheskii kontrol' zhirov i zhirozamenitelei. [Technochemical control of fats and fat substitutes]. Ed. O.B. Rudakov. St. Petersburg, 2011, 576 p. (in Russ.).

7. Metodika vypolneniia izmerenii massovoi doli vitaminov A i Ev probakh pishchevykh produktov i prodovol'stvennogo syr'ia na analizatore zhidkosti «Fliuorat-02». Metodika 04-07-96. [The method of measurement of the mass fraction of vitamins A and $\mathrm{E}$ in samples of foodstuffs and food sh-governmental raw liquid analyzer "Fluorat-02." Methods 4.7.96]. St. Petersburg, 1996, 39 p. (in Russ.).

8. Gosudarstvennaia Farmakopeia SSSR. [State Pharmacopoeia of the USSR]. XI ed. issue 2, Moscow, 1990, 642 p. (in Russ.).

9. Skurikhin I.M., Nechaeiv A.P. Vse o pishche s tochki zreniia khimika. [All of the food from the point of view of the chemist]. Moscow, 1991, 288 p. (in Russ.).

10. Patent 2524827(RU). 27.05.1997. (in Russ.).

11. Patent 2527295 (RU). 27.12.2014. (in Russ.).

12. Patent 254747 (RU). 10.04.2015. (in Russ.).

Received April 22, 2015

Revised May 26, 2015

\footnotetext{
* Corresponding author.
} 
